\title{
Difference between natural and artificial sweeteners: Histopathological studies on male albino rat's brain (hippocampus)
}

\author{
A. S. Mohamed", N. A. El-Shinnawy, S. A. Abd El-mageid \\ Department of Zoology, Women College for Arts, Science and Education, Ain Shams University, Egypt
}

\begin{abstract}
The present work is a trial to compare effect of short and long term administrations of sucrose as a natural widely used sweetener, aspartame as a synthetic non-caloric sweetener and stevia as a novel natural non-caloric sweetener on rats' brain hippocampus. This was achieved using 64 male albino rats. Rats were divided into four groups. The first group served as control group receiving distilled water. The second group represented the sucrose group receiving $10 \%$ sucrose solution (weight /volume). The third group served as aspartame group receiving aspartame $(75 \mathrm{mg} / \mathrm{kg}$ body weight /day).The fourth group represented the stevia group and received $(40 \mathrm{mg} / \mathrm{kg}$ body weight/day).Animals received different experimental treatments by oral gavage and they were dissected after a short duration of 30 days and long experimental duration of 90 days. Histological investigation of hippocampal sections of hippocampus revealed neuronal degeneration with pyknotic nuclei, dilatation and congestion in blood vessels and spongiform changes in the neuropil after both sucrose and aspartame treatments. On the other hand, stevia treatment to rats showed near to normal pattern of the granular and the neuropil. Histochemical, stained sections of Bromophenol blue stain to hippocampal tissue recorded significant decrease in protein content in hippocampus in sucrose group and aspartame groups respectively after 90 days compared with stevia and control rats. Staining hippocampus tissue of rats treated with sucrose or aspartame with Congo red stain revealed cellular homogenous pink deposits of amyloid throughout the hippocampus tissue. This was decreased and observed as limited or few amyloid depositions in stevia group compared to controls. In conclusion, Stevia, a non-calorific sweetener, is a better alternative to the synthetic sweetener aspartame because stevia has the potential to assist individuals in regulating their weights without any recognized side effects on hippocampus tissue besides its health benefits as a natural antioxidant.
\end{abstract}

Key words: Sucrose; Aspartame; Stevia; Histopathology.

* Corresponding author: aishasaber357@gmail.com 


\section{Introduction}

The brain tissue needs small amounts of sugar to function normally. Sweeteners as sugars are the best for supplying it. Sugars consisted largely of glucose, fructose and sucrose. One of the most common nutritive and caloric sweeteners in use today is sucrose (White, 2014). Sucrose is a very important ingredient in the food industry used in numerous products from cured meat to candies and ice-cream (Crestani et al., 2018). Excessive consumption of sugars can become pathological, leading to neuroadaptations similar to those induced by drugs of abuse. There is also evidence for a link between high sugar consumption and poorer cognitive function. In addition, high sucrose diets can cause poorer performance of hippocampal-dependent memory task (Kendig et al., 2013). Moreover, sucrose exposed rats showed deficits in recognition, memory task indicating that both prefrontal and hippocampal function was impaired (Reichelt et al., 2015). Hippocampus region is of particular interest in brain because it is critical for decision-making and various forms of memory ( $Y u$ and Frank 2014). Therefore, consumption of sugar substitutes especially low-calorie sweeteners may not stimulate appetite, thereby not increasing calorie intake and not promoting weight gain. These sweeteners may reduce most of the side effects expected from using sucrose sweetener (Abo Elnaga et al., 2016). Non caloric sweeteners are divided into artificial or synthetic non-nutritive sweeteners and natural of plant origin non caloric sweeteners (Neacşu and Madar, 2014). Aspartame, or N-(L- $\alpha$-Aspartyl)-L-phenylalanine, 1-methyl ester, is a low-calorie artificial sweetener, with the same caloric intake as sugar, $4 \mathrm{kcal} / \mathrm{g}$, but it is approximately 200 times sweeter and thus it is used in foods and beverages in very low amounts, resulting in low-calorie intake. Aspartame can be used as a table top sweetener and in beverages and a wide variety of prepared such as cereals, dairy products, chewing gum, packaged desserts, sauces, and syrups (Haighton et al., 2019). Most studies indicate that aspartame reduces food intake and may assist with weight control as it is used in the weight reduction regime (Anton et al., 2010). Aspartame consumption has negative impact on various neurological effects that include headache, insomnia and seizures, alterations in regional concentrations of catecholamine which is accompanied with behavioral disturbances (Ashok and Sheeladevi, 2014). Aspartame exposure causes increased production of free radicals and increased oxidative damage to proteins in brain. The impact of aspartame induced changes in brain is well represented in the histological alterations of hippocampal region (Onaolapo et al., 2017). Increasing consumer demands for healthy, low-caloric sweeteners of natural rather than synthetic origin as stevia has spurred the food industry's interests in using non- caloric sweeteners (Abo Elnaga et al., 2016). Stevia residue extract is a polyphenol-rich extract prepared from byproducts during steviol glycosides production that could be used for the prevention or alleviation of brain oxidative stress (Zhao et al., 2019). It is recognized to be 250 times sweeter than sucrose ( $4 \mathrm{~g} / \mathrm{L})$ and is used as non-caloric alternative to table sugar. Besides sweetness, many studies have reported the therapeutic benefits of glycosides derived from Stevia rebaudiana, which include anti-hyperglycemic, anti-hypertensive, antiinflammatory, anti-tumor, anti-diarrheal, diuretic, and immunomodulatory actions (Rotimi et al., 2018). Consumption of stevia gives better results and leads to better improvement of the histological picture of the different brain areas compared with aspartame administration (Mohamed, 2013). Therefore, the aim of the present study is to assess the histological and histochemical alterations in brain tissue specifically hippocampus sections from rats administrating sucrose as a high caloric widely used sweetener , aspartame (a synthetic sugar substitute) and stevia (a natural sugar substitute) for both short duration (30 days) and long duration (90 days). 


\section{Material and Methods}

\subsection{Experimental Animals:}

The current study was conducted using 64 Young male albino rats of strain Rattus Norvegicus. They weighed an average weight of $100 \pm 10 \mathrm{gm}$. The animals were housed in the vivarium of the Animal house of Medical Research and Bilharzia Center, Faculty of Medicine, Ain Shams University.

\subsection{Experimental Chemicals and Dosage:}

\section{A- Sucrose:}

Sucrose $\left(\mathrm{C}_{12} \mathrm{H}_{22} \mathrm{O}_{11}\right)$ is a disaccharide of molecular weight 342.20 . Sucrose was administrated orally to rats as $10 \%$ sucrose solution equivalent to $500 \mathrm{mg} / \mathrm{kg}$ body weight dissolved in distilled water (w/v). Sucrose was purchased from ADWIC (El-Nasr pharmaceutical chemicals Company Egypt). It was orally supplemented to rats for 90 consecutive days according to Kendig et al., (2013). This sucrose solution provides a caloric density of (approx. $0.4 \mathrm{kcal} / \mathrm{g}$ ) similar to most commercially available sugar drinks.

\section{B. Aspartame:}

Aspartame (1-methyl N-L-a- aspartyl -Lphenylalanine) was purchased as tablet formulation from (Amrya for pharmaceutical industries Alexandria - Egypt). Each tablet contains $20 \mathrm{mg}$ of aspartame (one tablet equal teaspoonful of sugar and 0.4 calorie). Tablets were dissolved in distilled water and given orally to rats at a dose of $75 \mathrm{mg} / \mathrm{kg}$ body weight /day for 90 consecutive days according to Ashok et al., (2014).

\section{Stevia:}

Stevia was purchased as a powder from Alpha Nexa Nutritionals Ltd, Kent (U.S.A.). Stevia was dissolved in distilled water and given orally as the calculated human therapeutic dose according to Paget and Barnes, (1964) at a dose of $40 \mathrm{mg} / \mathrm{kg}$ body weight/day for 90 consecutive days.

\subsection{Histological Investigation}

For general histological examination; hippocampus sections were stained as a routine in Harris's alum Haematoxylin and Eosin (Bancroft and Cook, 1994).

\subsection{Histochemical Investigations}

For the demonstration of particular histochemical features, the following staining techniques were employed: 
i. Bromophenol blue according to Mazai et al., (1953), for the demonstration of sites of total protein content.

ii. Congo red stain according to Puchtler et al., (1962), to demonstrate amyloid deposits in tissue sections.

Different histochemical features were analyzed quantitatively in the Regional center of Mycology and Biotechnology (Al-Azhar University) using image analyzer Unit Olympus BX40.

\subsection{Statistical Analysis}

Image analysis of hippocampus sections stained by different histochemical stains were expressed as mean \pm standard error of means (SE). All recorded data were analyzed using the Statistical Processor System Support (SPSS) version 10computer program. The significance of differences between means of the control and all treated rats were analyzed using one-way analysis of variance (ANOVA) test.

\section{Results}

\subsection{Histological Investigation}

On the microscopic level, hippocampus sections stained with H\&E revealed normal hippocampus formation of Hippocampus proper, dentate gyrus and Subiculum. Hippocampus proper is formed of Cornu Ammonis (CA). $\mathrm{CA}_{1}$ and $\mathrm{CA}_{2}$ are formed of zones of small pyramidal cells while $\mathrm{CA}_{3}$ and $\mathrm{CA}_{4}$ are formed of zones of large pyramidal cells. $\mathrm{CA}_{4}$ projects into concavity of dentate gyrus that is formed of small granule cells. Subiculum is outward continuation of $\mathrm{CA}_{1}$ region. Areas in between compact zones of cells comprise the molecular layer which consists of neuronal processes (axons and dendrites), glial cells and scattered nerve cells (Fig.1-a). Pyramidal cells are pyramidal multipolar nerve cells. The apex and lateral sides give off several dendrites. The axon arises from the base of the cell body. (Cornu Ammonis CA). Granular cells are polygonal small nerve cells. These cells have multiple branching dendrites and relatively short axon. (Dentate gyrus). Molecular layer is formed of parallel fibers from cells of other deeper layers (Subiculum) and it shows many glial cells among neuronal processes (Fig.1-b)

Microscopical examination showed abnormal alteration of hippocampus sections post sucrose treatment at 30 days, this was designated in the form of neuronal degeneration in dentate gyrus with pyknotic nuclei and fewer of pyknotic pyramidal cells. Moreover, other histological features were variably present that included small number of hippocampal pyramidal cells shrunken with condensed and deeply stained nuclear chromatin (Fig.1-c). Later on, with the advance of time i.e. 90 days post sucrose treatments, degeneration, necrosis in pyramidal layer and vacuolation in glial cells were also manifested. Vacuolated molecular layer, dilatation and congestion in blood vessels were observed (Fig.1d).

Histological examination of hippocampus of rats revealed great pathological deviations from normal pattern post aspartame treatment which lasted till the end of experimentation i.e. 90 days. Histological hippocampus changes were first manifested from the $30^{\text {th }}$ days post aspartame treatment; this was 
characterized by dilatation and congestion of blood vessels with inflammatory infiltrative cells (Fig.1-e). Moreover, other histological features were variably present that included less number of pyramidal cells in CA3 layer and pyknotic nucleus associated with vacuolation of the glial cells in molecular layer. Neuronal degeneration in dentate gyrus with congestion in blood vessels, hemorrhage and spongiform (micro vacuolated) changes in the neuropil (Fig.1-f) were also prominent features. At the end of the experimental period i.e. 90 days post aspartame treatment more severe lesions were detected, degenerative neural cells with spare chromatin material and vacuolation in the neuropil were seen. Degeneration in neural cells with less aspersed chromatin material that was clumped to the inner side of nuclear membrane and other shrunken neurons with pyknotic nuclei were observed (Fig.1-g). Moreover, other histological features were variably present including dilatation and congestion of blood vessels with inflammatory infiltrative cells and condensation of chromatin material in neurons, swollen and degeneration in the neuropil. Also, it was observed that there was degeneration, necrotic granular cells and vacuolation in the molecular layer, condensation of the granular layer and pyknotic nuclei in pyramidal neurons and diffused gliosis in the neuropil.

Hippocampus of the group of rats administrating stevia manifested mild abnormal alteration of hippocampus sections at the start of the experiment period i.e. 30 days. This was designated in the form of few number of pyramidal cells that were shrunken with condensed and deeply stained nuclear chromatin, neuronal degeneration with hemorrhages. Also, mild congestion in blood vessels with perivascular edema and near to normal molecular features were seen (Fig.1-h). By the $90^{\text {th }}$ day, the histological picture of the hippocampus sections from rats showed slight damage as designated by neuronal in the molecular layers, swollen neurons in the neuropil, infiltrate of inflammatory cells and mild dilatation in blood vessels in the neuropil. On the other hand, most areas appeared near to normal pattern of the granular and the neuropil (Fig.1-i).
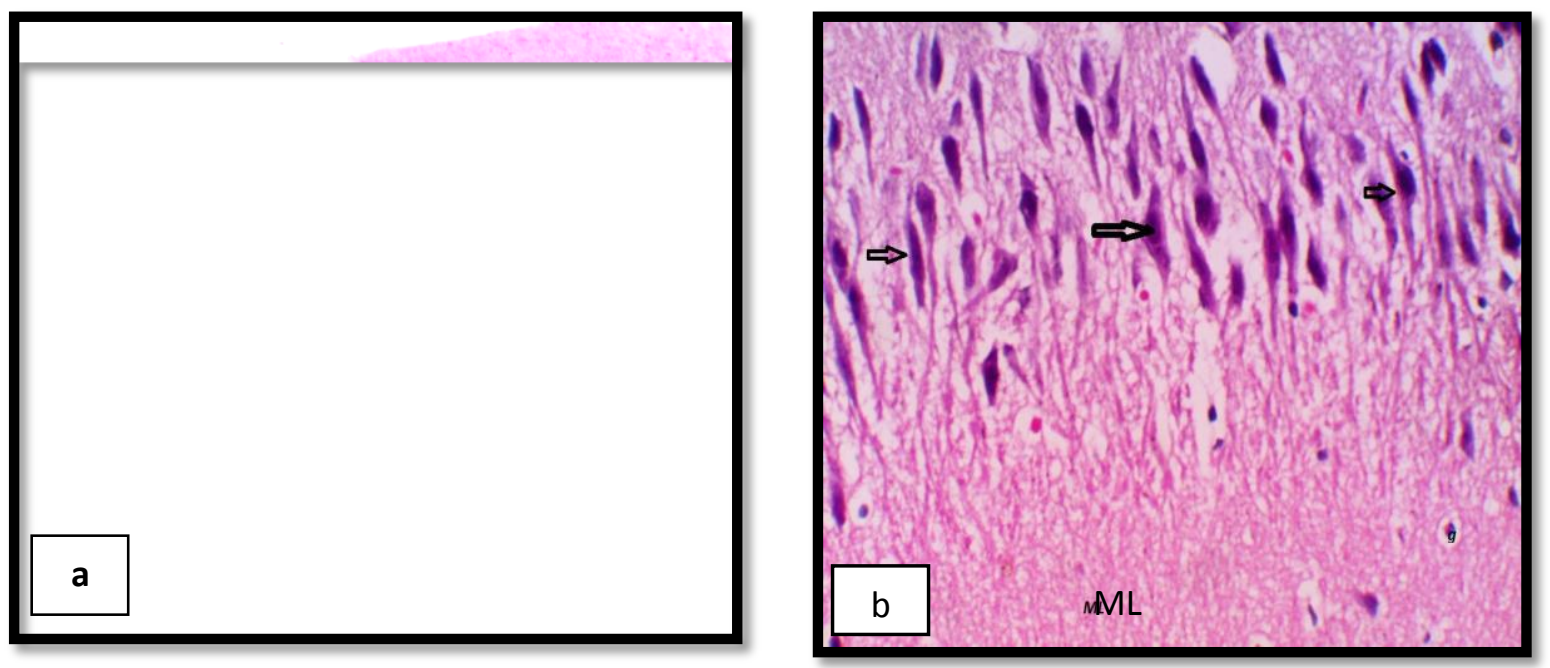

Fig. ( $1 \boldsymbol{a}$ ) : Photomicrograph of hippocampusFig (1b): Photomicrograph section from section from normal control rat showing thehippocampus of normal control rats showing 
different areas of the hippocampal formationcompact layers of large pyramidal cells in where the hippocampus proper is formed of the $\mathrm{CA}_{3}$ region, with vesicular nuclei (arrows). Cornu Ammonis $\mathrm{CA}$ as $\left(\mathrm{CA}_{1}, \mathrm{CA}_{2}, \mathrm{CA}_{3} \& \mathrm{CA}_{4}\right)$ Molecular layer (ML) shows many glial regions and is continued ascells among neuronal processes. (H\&E Subiculum(S).Dentate gyrus (DG) is seen $\times \mathbf{2 5 0}$ ) surrounding $\mathrm{CA}_{4}$.(ML) denotes molecular layer inside concavity of CA and DG. $(\mathbf{H} \& \mathbf{E} \times \mathbf{4 0})$
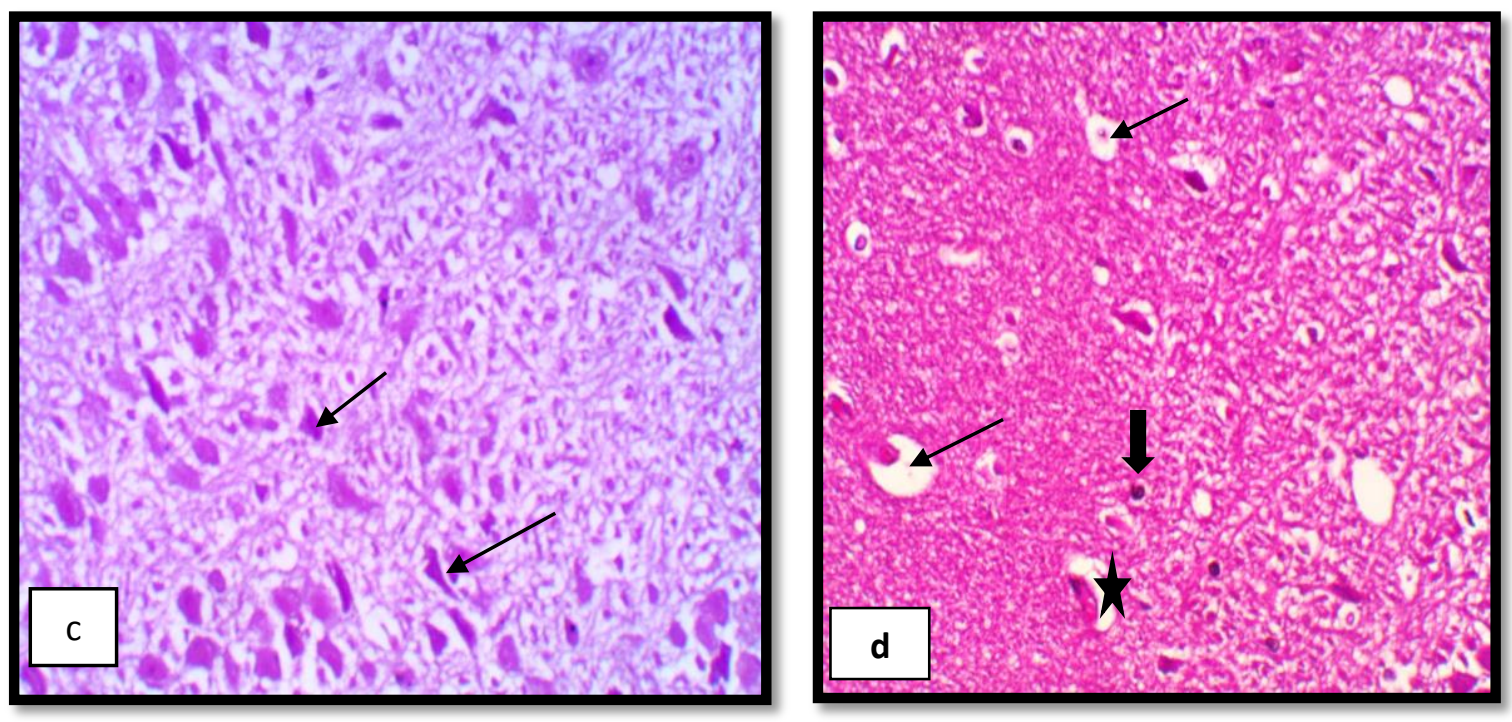

Fig (1c): Photomicrograph of hippocampusFig (1d): Photomicrograph of hippocampus section from rat after 30 days treatment of section of Sucrose group after 90 days Sucrose showing number of hippocampalshowing vacuolar degeneration (arrows) in pyramidal cells shrunken with condensed and some glail cell, some other shrunken deeply stained nuclear chromatin (arrows). neurons with pyknotic nuclei (arrow head) $(\mathbf{H} \& \mathbf{E} \times 250)$ and dilated blood vessel (star). (H\&E × 200) 

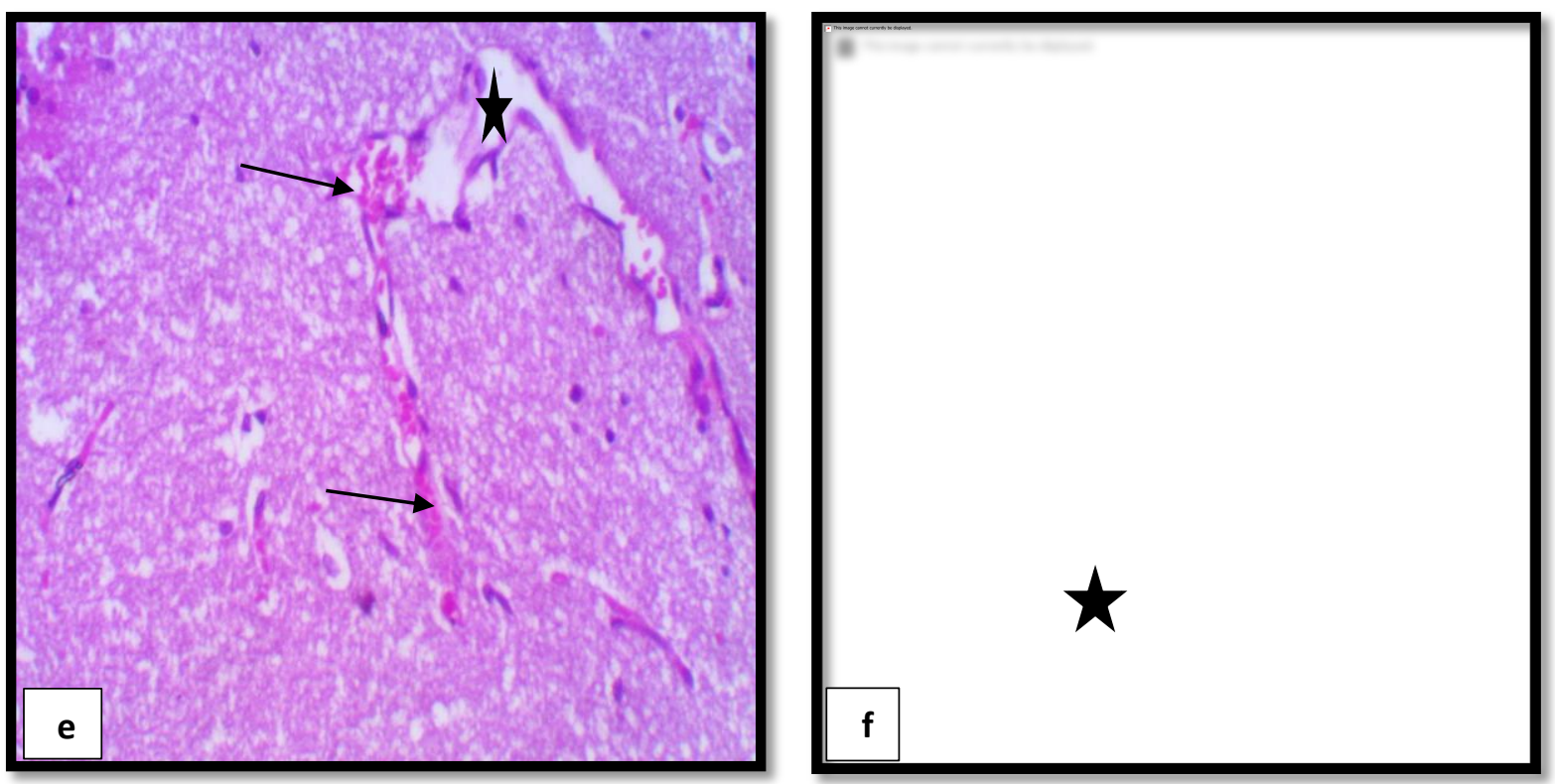

Fig (1e): Photomicrograph of hippocampusFig (1f): Photomicrograph of hippocampus section of rat from Aspartame group after 30 section of rat from Aspartame group after 30 days showing dilatation (star) and congestiondays showing spongiform (micro vacuolated) (arrows) of blood vessels with inflammatorychanges (star) in the neuropil. $(\mathbf{H} \& \mathbf{E} \times \mathbf{2 0 0})$ infiltrative cells. $(\mathbf{H} \& \mathbf{E} \times \mathbf{2 0 0})$
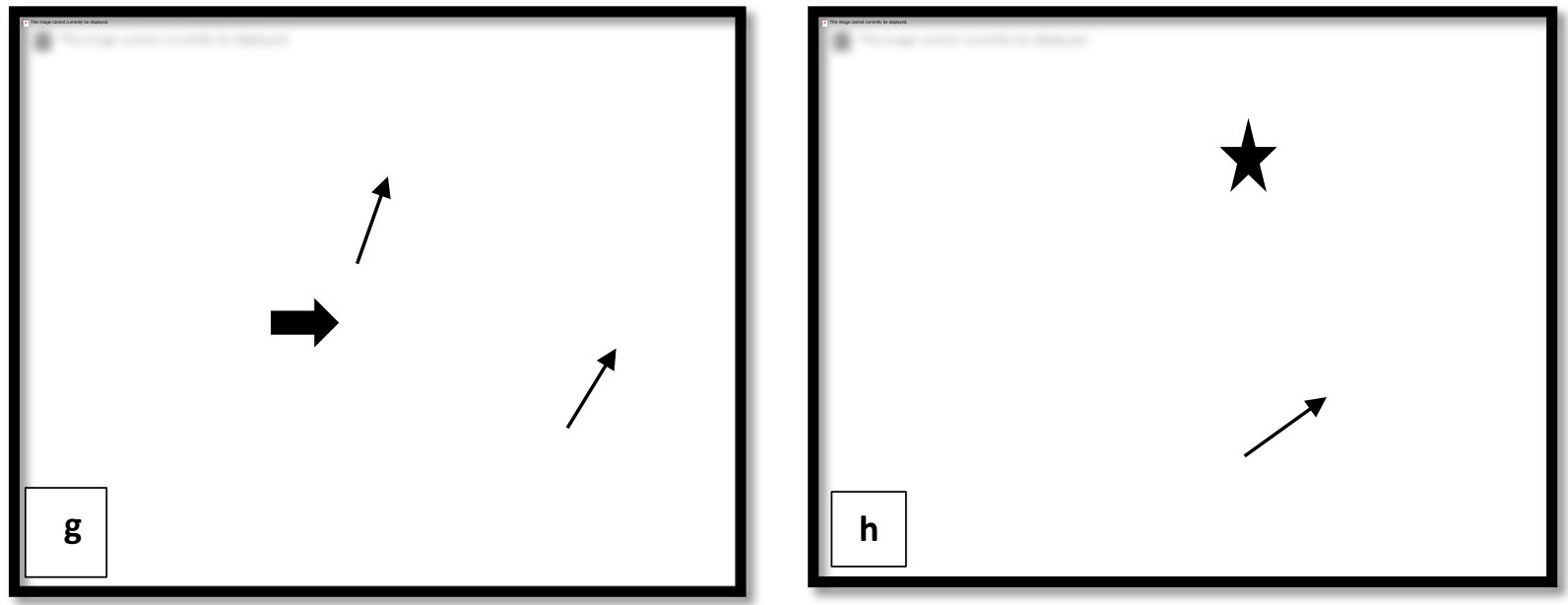

Fig (lg ): Photomicrograph of hippocampusFig (lh): Photomicrograph of hippocampus section of Aspartame group after 90 dayssection of rat from Stevia group after 30 days showing degeneration in neural cells with lesser showing mild congestion in blood vessels with dispersed chromatin material that was clumpedperivascular edema (arrow) and near to normal to the inner side of nuclear membrane (arrows) 
and other shrunken neurons with pyknotic molecular layer (star). (H\&E $\times \mathbf{2 0 0})$ nuclei (arrow head). (H\&E $\times \mathbf{2 5 0})$

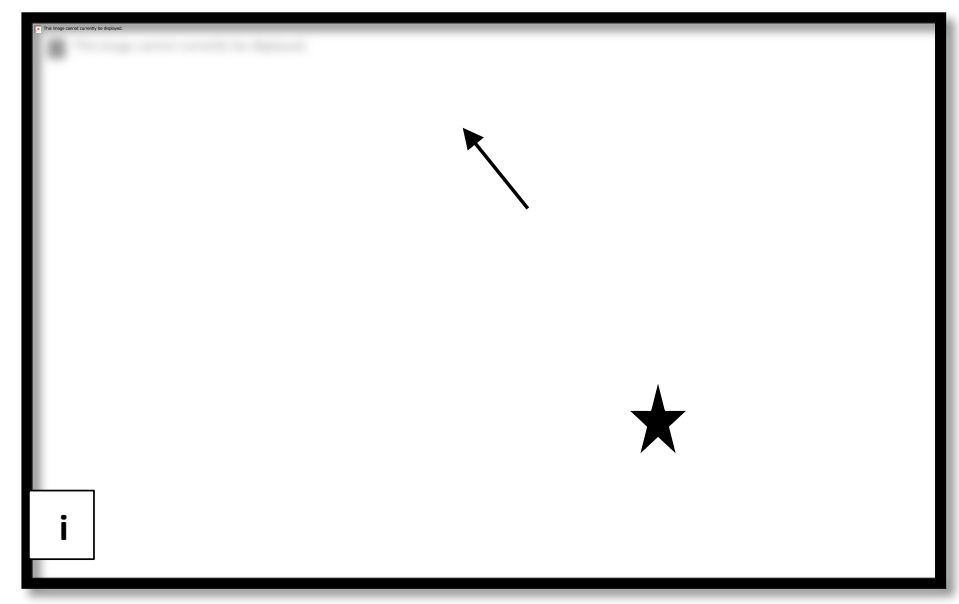

Fig (1i): Photomicrograph of hippocampus section of Stevia group after 90 days showing near to normal pattern apparent of the granular (arrow) and the neuropil (star) layers. $(\mathbf{H} \& \mathbf{E} \times 200)$

\subsection{Histochemical Investigation:}

\subsubsection{Total protein content}

Bromophenol blue stained hippocampus sections from control group of rats revealed uniform distribution of protein granules in cytoplasm and nuclei in both cornu ammonis, dentate gyrus and molecular layers as well as neuronal processes and connective tissues (Fig.2-a). Hippocampus sections of rats given sucrose for 30 days manifested a gradual moderate decrease in the protein content where the staining ability of the cytoplasm and nucleus was moderately decreased (Fig.2-b). At the end of the 90 days a marked decreased protein content was detected, still this reduction was highly significant when compared to normal levels (Fig.2-c). Alternatively, examination of hippocampus sections of aspartame supplemented rats showed decrease in the pattern of stainability of the total protein in the different constituents of the hippocampus tissue in comparison with controls commencing from the 30 days (Fig.2d) and passing through the whole experimental period. This decrease in protein content persisted revealing highly significant decrease in staining status by 90 days post investigation (Fig.2-e). The decrease in total protein was manifested mostly in the irregular patches that persisted till the end of experimentation. On the other hand, the identification of total protein content of hippocampus from rats given stevia for 30 days revealed more or less normal distribution of protein material (Fig.2-f). No detectable changes in total protein distribution throughout the 90 days of experimental period were recognized (Fig.2-g). Applying the bromophenol blue technique, total protein content distribution in hippocampus tissue is demonstrated in (Fig.3). 

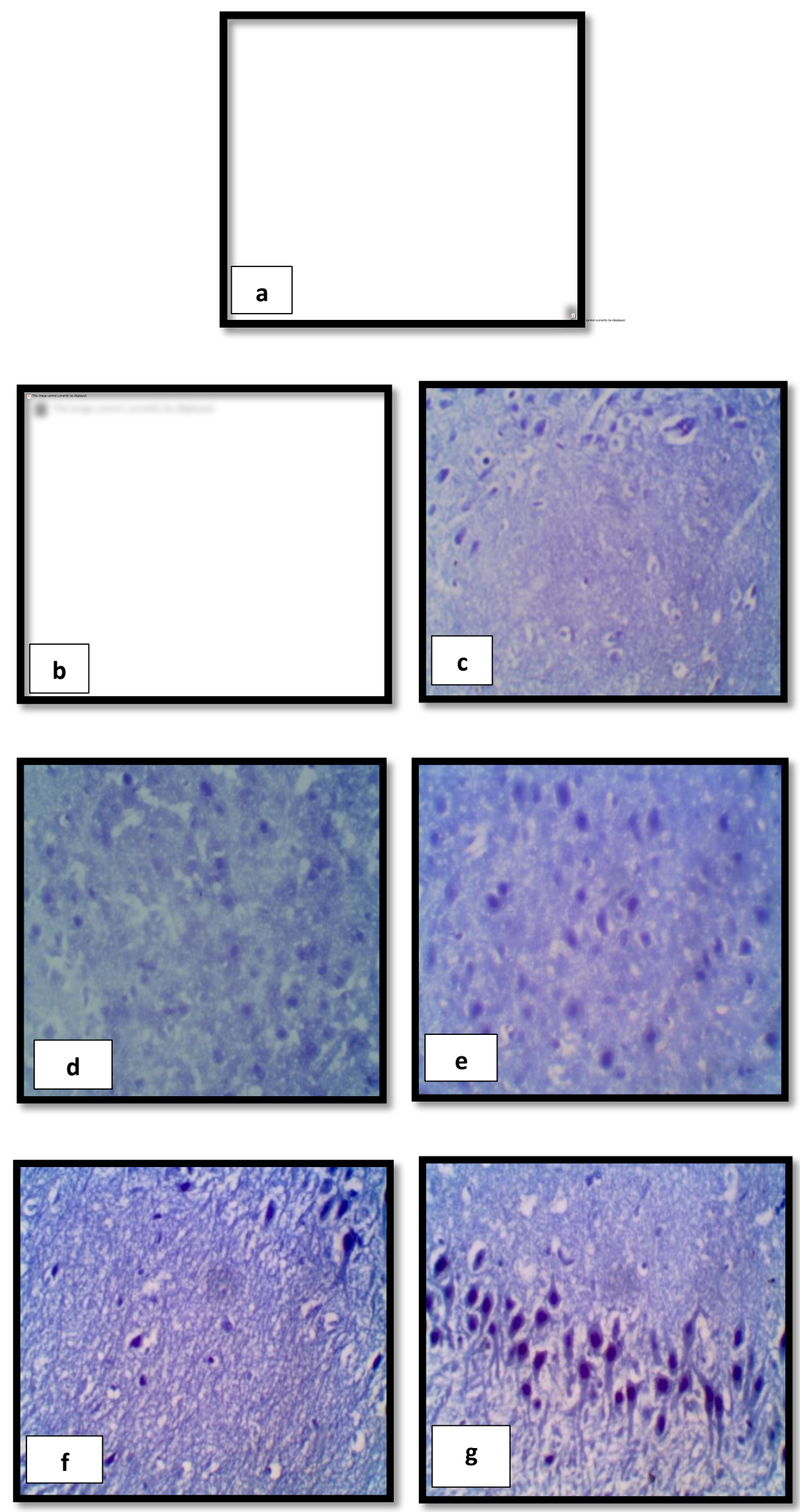
Fig. (2): photomicrograph of hippocampus section:

a) Photomicrograph of rat hippocampus sections from control group showing uniform distribution of protein content in hippocampus tissue (Bromophenol blue; $\times \mathbf{4 0 0}$ ).

b) Photomicrograph of rat hippocampus sections from sucrose group after 30 days showing decrease of protein content in hippocampus tissue (Bromophenol blue; $\times 400)$.

c) Photomicrograph of rat hippocampus sections from sucrose group after 90 days showing decrease in total protein content in the different types of hippocampus tissue (Bromophenol blue; $\times 400$ ).

d) Photomicrograph of rat hippocampus sections from aspartame group after 30 days showing decrease in staining affinity of protein content in hippocampus tissue (Bromophenol blue; $\times 400$ ).

e) Photomicrograph of rat hippocampus sections from aspartame group after 90 days showing marked decrease in total protein content in the irregular patches (Bromophenol blue; $\times 400)$.

f) Photomicrograph of rat hippocampus sections from stevia group after 30 days showing more or less normal distribution of total protein content (Bromophenol blue; $\times 400)$.

g) Photomicrograph of rat hippocampus sections from stevia group after 90 days showing normal distribution of protein material (Bromophenol blue; $\times 400$ ).

Fig.(3): Image analysis of hippocampus sections of rats showing a uniform distribution of the mean values of protein content and the significant intensity between control and experimental groups. 


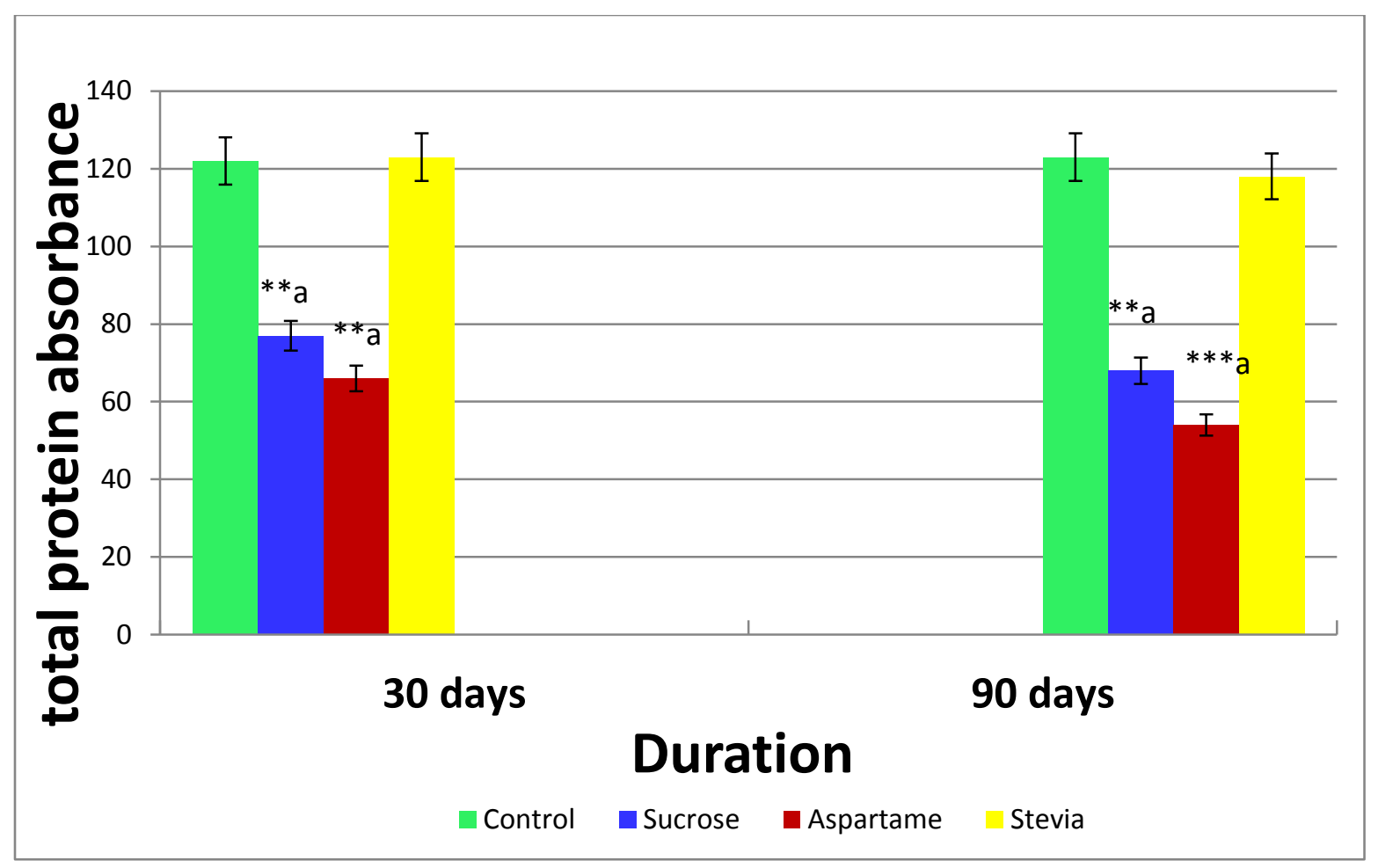

${ }^{a}$ All experimental groups compared with the control group. ${ }^{*}$ Significant; ${ }^{* *}$ highly significant; ${ }^{* * *}$ very highly significant.

\subsubsection{Amyloid}

Congo red staining of hippocampus tissue belonging to normal control group manifested absence of amyloid. (Fig. 4-a). The examination of hippocampus from rats treated with sucrose revealed, orange-red deposits of amyloid starting from 30 days post treatment and persisted till the end of the investigation i.e. 90 days. (Fig. 4- b) and (Fig.4-c).

On the other hand, Congo red staining of hippocampus from rats treated with aspartame manifested cellular homogenous pink deposits of amyloid throughout the hippocampus tissue and this commenced from the first days and persisted till the end of experimentation i.e. 90 days. (Fig. 4-d) and (Fig. 4-e). 
Rats treated with stevia verified limited or few amyloid depositions at the commencement of experimentation which persisted till the end of the study i.e. 90 days. (Fig. 4-f).
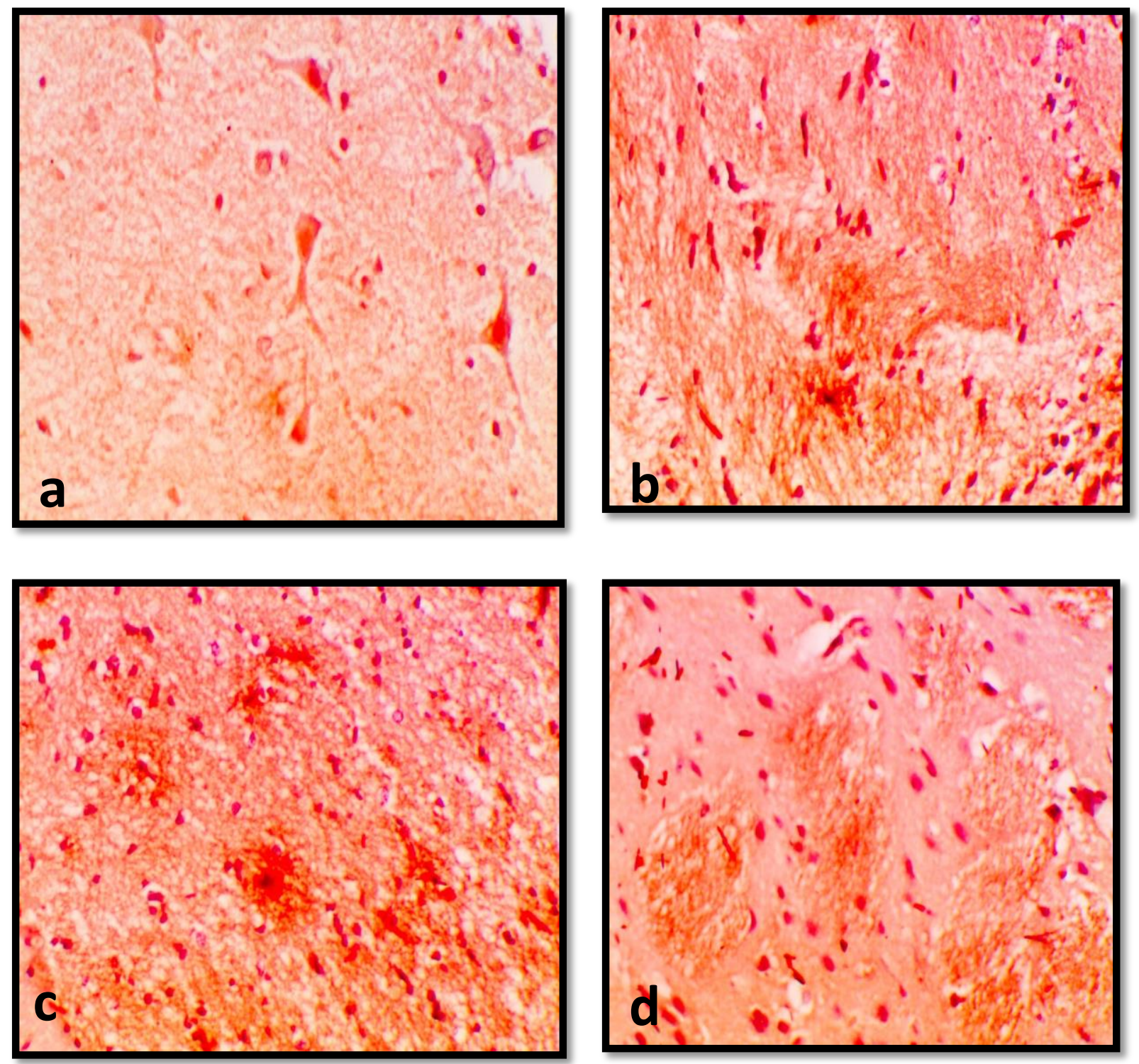

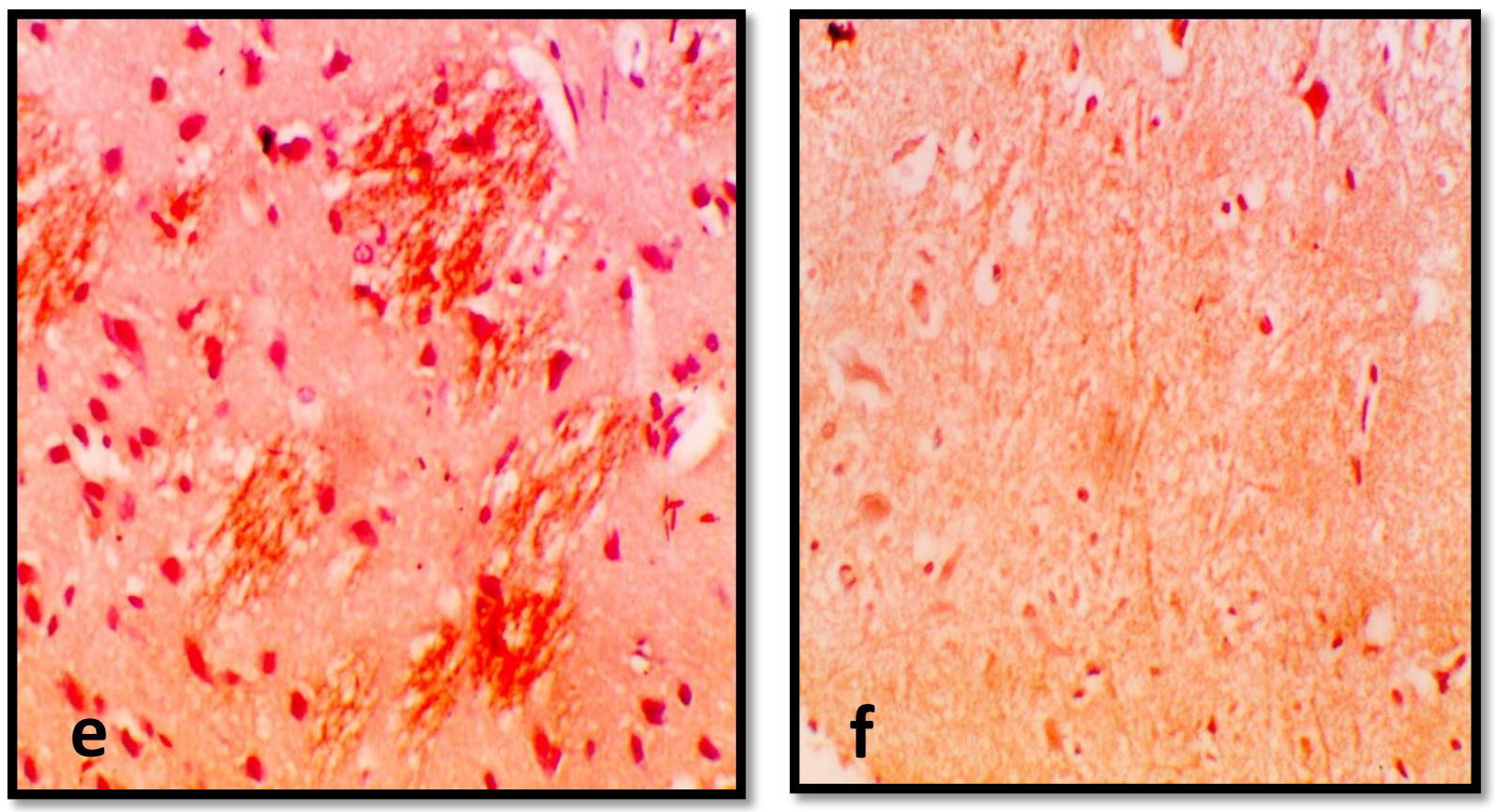

Fig. (4): photomicrograph of rat hippocampus sections:

a) Photomicrograph of rat hippocampus sections from control group showing few amyloid (Congo red; $\times 250$ ).

b) Photomicrograph of rat hippocampus sections from sucrose group after 30 days showing orangered deposits of amyloid (Congo red; $\times \mathbf{2 5 0}$ ).

c) Photomicrograph of rat hippocampus sections from sucrose group after 90 days showing amyloid deposits (Congo red; $\times \mathbf{2 5 0}$ ).

d) Photomicrograph of rat hippocampus sections from aspartame group after 30 days showing amyloid deposits (Congo red; ×250).

e) Photomicrograph of rat hippocampus sections from aspartame group after 90 days showing cellular homogenous deposits of amyloid throughout the whole hippocampus tissue (Congo red; $\times 250$ ).

f) Photomicrograph of rat hippocampus sections from stevia group after 90 days showing limited amyloid deposit (Congo red; $\times \mathbf{2 5 0}$ ).

\section{Discussion}

This study was conducted to compare aspartame as a synthetic non-caloric sweetener and stevia as a natural non-caloric sweetener with sucrose as a generally used sweetener. This comparative work was 
based on studying the alterations in histological and histochemical features of hippocampus tissue. Oral sucrose administration at a dosage of $5 \mathrm{mg} / \mathrm{kg}$ body weight/day to rats for 90 consecutive days manifested degeneration, necrosis in pyramidal layer and vacuolation in glial cells. Vacuolated molecular layer and dilatation and congestion in blood vessels were also observed. These results were in accordance with (Kendig et al., 2013) who stated that consuming high sugar solution for long time can become pathological to the brain tissue leading to neuroadaptations similar to those induced by addictive drugs. In addition, sucrose treated rats demonstrated poorer spatial recognition with impairments in memory functions (Van Der Zwaluw et al., 2014)

Aspartame is composed of phenylalanine, aspartic acid and methanol. When aspartame enters the body, it is hydrolyzed to form formaldehyde and formic acid which is the main cause of neurological and behavioral alterations (Ashok et al., 2013) Additionally, formaldehyde is known to be a neurotoxin and carcinogen (Humphries et al., 2008)

The impact of aspartame induced changes in brain is well represented in the histology of hippocampal regions in this study. Histological examination of hippocampus tissue of rats post aspartame treatment revealed dilatation and congestion of blood vessels with inflammatory infiltrative. Moreover, other histological features were variably present that included less number of pyramidal cells in CA3 layer and pyknotic nuclei associated with vacuolation of the glial cells in molecular layer. Neuronal degeneration in dentate gyrus hemorrhage and spongiform (micro vacuolated) changes in the neuropil were also prominent features. At 90 days post aspartame treatment degenerative neural cells, degeneration in neural cells with aspersed chromatin material that was clumped to the inner side of nuclear membrane and other shrunken neurons with pyknotic nuclei were also observed. These results were in accordance with (Onaolapo et al., 2017) who revealed that repeated administration of aspartame was associated with a dose-related progression of neuronal injury. A number of studies were in consistent with the results of this study reporting neuronal degeneration as evidenced by increased cytoplasmic vacuolations, pyknosis, karyorhexis and karyolysis under long term aspartame administration (Abd El-Samad, 2010). Aspartame associated changes in neuronal morphology have been reported to be mediated by the generation of large numbers of both nitrogen and oxygen free-radical species that have been shown to damage cellular proteins and DNA, especially the mitochondrial DNA (Burda and Sofroniew, 2014). The results of the present study were in accordance with (Ashok and Sheeladevi, 2014) who emphasized that H\&E staining to the hippocampus tissue of aspartame treated animals showed neuronal shrinkage of hippocampal layer due to degeneration of pyramidal cells. The alterations in brain hippocampal region were manifested as abnormal neuronal morphology of pyramidal cell layers of Cornu Ammonis 1, 2 and 3 and denate gyrus. In addition aspartame administration resulted in disorganized morphology of pyramidal cell layers with less intense stain. As well, hematoxylin and eosin stained hippocampus tissue showed cellular apoptosis in aspartame group which may be probably due to the altered free radical scavenging enzymatic and non-enzymatic systems (Villareal et al., 2016).

Morphologic mechanism of the neuronal injury in the pyramidal cell layer of hippocampus tissue because of aspartame administration is thought to be due to a gradual cell loss with a decrease in width of the stratum pyramidal layer. In the dentate gyrus, there is cell death, with an increase in the width of the 
ascending and descending limbs of the dentate gyrus and haziness/blurring of the cell margins, which is suggestive of oedema (Onaolapo et al., 2017). This induced neuronal injury has been linked to an increase in the expression of proapoptotic markers; with a simultaneous decrease in the expression of anti-apoptotic markers (Deng et al., 2010). Again, Ashok et al., (2018) demonstrated that aspartame treated animals showed a neuronal shrinkage of hippocampal neurons, degeneration of hippocampal layer with abnormal neuronal morphology of pyramidal cell layers of Cornu Ammonis and disorganized pyramidal cell layers morphology. On the contrary, Abhilash et al., (2013) revealed that staining brain tissue with $H \& E$ exhibited mild vascular congestion with normal neuronal cell architecture and there was no vascular or inflammatory changes in brain tissue under $40 \mathrm{mg} / \mathrm{kg}$ body weight of aspartame due to a potential limitation have used a small set of samples for histopatological investigations. So, to confirm this findings and to understand the exact mechanism behind the vascular congestion, a detailed investigation with a large sample size is necessary.

Quite the reverse, hippocampus tissue of the group of rats administrating stevia manifested mild abnormal alteration of hippocampus sections at 30 days. This was designated in the form of few number of pyramidal cells that were shrunken with condensed and deeply stained nuclear chromatin. By the $90^{\text {th }}$ day, the histological picture of the hippocampus sections from rats showed slight damage where most areas appeared with near to normal pattern of the granular and the neuropil areas.

The present study also confirmed a decrease in hippocampal tissue total protein with an increase in amyloid deposits under sucrose administration revealing the alterations in hippocampus under long term sucrose administration (Avena et al., 2008). Still, the present study elucidated a decrease in the pattern of stainability of the total protein in the different constituents of the hippocampus tissue in comparison with controls through the whole experimental period. On the other hand, Congo red staining of hippocampus from rats treated with aspartame manifested increase in cellular homogenous pink deposits of amyloid throughout the hippocampus tissue. Aspartame metabolites induced amino acids imbalance within neuron micro environment, thus producing ultimate damage to the brain cells (Ashok et al., 2015). Furthermore, formaldehyde is attached to the DNA, RNA and proteins of the brain cells and becomes difficult to be removed. This might cause breaks in the DNA of brain cells (Ashok et al., 2014). In addition, excessive aspartame stimulation could trigger the generation of large numbers of free radical species. The free radical generation leads to the alteration in antioxidant system, which induces oxidative stress leading to the cellular level damage in the brain cellular proteins and DNA (Ashok 2013). Also, free radicals had been shown to prevent uptake of excitotoxins by astrocytes as well, which would significantly increase extra cellular aspartame metabolites levels. This creates a vicious cycle that would multiply any resulting damage and malfunction in the neural cells (Ashok et al., 2017)

Also, the identification of total protein content of hippocampus from rats given stevia revealed more or less normal distribution of protein material with no delectable changes in total protein distribution throughout the 90 days of experimental period. Rats treated with stevia verified limited or few amyloid depositions after 90 days. In accordance with the histological features from hippocampus tissue of this 
study, (Guzman et al., 2018) confirmed the normal cytoarchitecture of brain tissue. Also, the welldefined form of the cellular and nuclear membrane become evident in the brain tissue of animals supplementing stevia with thin chromatin and homogenous neuropil. The brain analyzed structures confirmed no present evident damage under stevia sweetener administration. However, a slight protective effect of stevia against damage in the cortex has also been achieved. This may be due to the increase in GSH concentration in striatum of animals suggesting the neuroprotection and antioxidant effects of stevia on brain tissue. Furthermore, the neuroprotection effect of stevia could be due to the polar compounds present in stevia like chlorophylls, phenolic substances and flavonoids. (Ruiz Ruiz et al., 2014). This study demonstrated the anti-inflammatory effects of stevioside present in stevia (Anton et al., 2010). In addition, stevia possess as high antioxidant capacity because Stevia is rich in phenolic compounds such as chlorogenic acids that may protect against oxidative damage (Sharma et al., 2012). The results of this study focuses on normal brain architecture under stevia administration compared to the altered histological brain tissue under aspartame administration. These results were confirmed by (Mohamed, 2013) who evidenced that the recovery of stevioside was better than that of aspartame as evidenced by normal histological appearance of brain cells and less-vacuolated neuropils.

\section{Conclusion}

In conclusion, the aqueous extract of stevia rebaudiana may have the potential to be used as a natural sweetener alternative to the synthetic sweetener aspartame. Stevia could be used as an accessible source of natural antioxidants with resultant health benefits.

\section{References}

Abd El-Samad, A.A. (2010): Light and electron microscopic study on the effect of aspartame on the cerebellar cortex of male albino rat. Egypt. J. Histol. 33(3):419-30.

Abhilash, M.; Paul, M.V.S.; Varghese, M.V. and Nair, R.H. (2013): Long-term consumption of aspartame and brain antioxidant defense status. Drug Chem Toxicol, 36(2):135-140.

Abo Elnaga, N.I.E.; Massoud, M.I.; Yousef, M.I. and Mohamed, H.H.A. (2016): Effect of stevia sweetener consumption as non-caloric sweetening on body weight gain and biochemical's parameters in overweight female rats. AOAS, http://dx.doi.org/10.1016/j.aoas.2015.11.008.

Anton, S.D.; Martin, C.K.; Han, H.; Cefalu, W.T.; Geiselman, P. and Williamson, D.A. (2010): Effects of stevia, aspartame, and sucrose on food intake, satiety, and postprandial glucose and insulin levels. Appetite, 55: 37-43.

Ashok, I. and Sheeladevi, R. (2014): Biochemical responses and mitochondrial mediated activation of apoptosis on long-term effect of aspartame in rat brain. Redox Biol, 2:820-831. 
Ashok, I.; Ananth, K.K.; Citarasu, T.; Wankhar, W.; Wankhar, D.; Sambantham, S.; Ravindran, R. and Sheeladevi, R. (2018): Oxidative stress evoked damages leading to attenuated memory and inhibition of NMDAR-CaMKII-ERK/CREB signalling on consumption of aspartame in rat model. JFDA, 26:903-916.

Ashok, I.; Sheeladevi, R. and Wankhar, D. (2013): Effect of long-term aspartame (artificial sweetener) on anxiety, locomotoractivity and emotionality behavior in Wistar Albino rats. Biomed Prev Nutr, http://dx.doi.org/10.1016/j.bionut.2013.04.002.

Ashok, I.; Sheeladevi, R. and Wankhar, D. (2013): Long term effect of aspartame (Artificial sweetener) on membrane homeostatic imbalance and histopathology in the rat brain. Free Radicals and Antioxidants, 3: S42-S49.

Ashok, I.; Sheeladevi, R. and Wankhar, D. (2014): Acute effect of aspartame-induced oxidative stress in Wistar albino rat brain. JBR, doi:10.7555/JBR.28.20120118

Ashok, I.; Wankhar, D.; Loganathan, S.; Shanmugam, S.; Rajan, R. and Rathinasamy, S. (2017): Disruption of redox homeostasis in liver function and activation of apoptosis on consumption of aspartame in folate deficient rat model. J Nutr Intermed Metab, 8:41-50.

Ashok, I.; Wankhar, D.; Wankhar, W. and Sheeladevi, R. (2015): Neurobehavioral changes and activation of neurodegenerative apoptosis on long-term consumption of aspartame in the rat brain. NLM, 2:76-85.

Avena, N.M.; Rada P. and Hoebel B.G. (2008): Evidence for sugar addiction: behavioral and neurochemical effects of intermittent, excessive sugar intake. Neurosci Biobehav Rev, 32:20-39.

Bancroft, J.D. and Cook, H.C. (1994): Manual of histological techniques and their diagnostic application. 2nd ed. Edinburgh: Churchill Livingstone, 23-26.

Burda, J.E. and Sofroniew, M.V. (2014): Reactive gliosis and the multicellular response to CNS damage and disease. Neuron, 81(2): 229-248.

Crestania, C.E.; Bernardo, A.; Costa, C.B.B. and Giulietti, M. (2018): Experimental data and estimation of sucrose solubility in impure solutions. J. Food Process Eng., 218:14-23.

Deng, W.; Aimone, J.B. and Gage, F.H. (2010): Neurons and new memories: How does adult hippocampal neurogenesis affect learning and memory? Nature Rev Neurosci, 11(5): 339-350.

Guzman, D.C.; Herrera, M.O.; Peraza, A.V.; Brizuela, N.O.; Garcia, E.H.; Olguin, H.J.; Mejia, G.B.; Angel, D.S.D. and Alberto Rojas Ochoa, A.R. (2018): Biochemical and histological changes produced by sweeteners and cytarabine in the brain of young rats. Nutr Hosp, 35:194-200.

Haighton, L.; Roberts, A.; Jonaitis, T. and Lynch, B. (2019): Evaluation of aspartame cancer epidemiology studies based on quality appraisal criteria. RTP, https://doi.org/10.1016/j.yrtph.2019.01.033. 
Humphries, P.; Pretorius, E. and Naude, H. (2008): Direct and indirect cellular effects of aspartame on the brain. Eur. J. Clin. Nutr. 62(4):451-462.

Kendig, M.D.; Boakes, R.A.; Kieron B. Rooney, K.B. and Corbit, L.H. (2013): Chronic restricted access to $10 \%$ sucrose solution in adolescent and young adult rats impairs spatial memory and alters sensitivity to outcome devaluation. Physiol. Behav., 120: 164-172.

Mazai, D.; Brewe, P.A. and Affert, M. (1953): "The cytochemical staining and measurement of protein with mercuric bromophenol blue". Biol. Bull. J., 104: 57- 64.

Mohamed, N.A. (2013): Chronic effect of aspartame versus stevioside on the cerebellar cortex of the adult albino rat: a histological and immunohistochemical study. Egypt. J. Histol., 36:213-232.

Neacşu, N.A. and Madar, A. (2014): Artificial sweeteners versus natural sweeteners. Econ. Sc., 7: 59-64.

Onaolapo, A.Y.; Onaolapo, O.J. and Nwoha, P.U. (2016): Alterations in behaviour, cerebral cortical morphology and cerebral oxidative stress markers following aspartame ingestion. $\mathrm{J}$ Chem. Neuroanat., http://dx.doi.org/doi:10.1016/j.jchemneu.2016.08.006.

Onaolapo, A.Y.; Onaolapo, O.J. and Nwoha, P.U. (2017): Aspartame and the hippocampus: Revealing a bi-directional, dose/time-dependent behavioural and morphological shift in mice. NLM, 139:76-88.

Paget, G.E. and Barnes, J.M. (1964): Toxicity tests. In: Laurence DR, Bacharach AL (1st ed.) Evaluation of drug activities. Pharmacometrics London: Academic Press: 161.

Puchtler, H.; Sweat, F. and Levine, M. (1962): On binding of congo red by amyloid. J. Histochem. Cytochem, 10: 355.

Reichelt, A.C.; Killcross, S.; Hambly, L.D.; Morris, M.J. and Westbrook, R.F. (2015): Impact of adolescent sucrose access on cognitive control, recognition memory, and parvalbumin immunoreactivity. Learn. Mem., 22: 215-224.

Rotimi, S.O.; Rotimi, O.A.; Adelani, I.B.; Onuzulu, C.; Obi, P. and Okungbaye, R. (2018): Stevioside modulates oxidative damage in the liver and kidney of high fat/low streptozocin diabetic rats. Heliyon, 4:e00640.

Ruiz Ruiz, J.C.; Moguel Ordonez, Y.B.; Matus Basto, A. and Segura Campos, M.R. (2014): Antioxidant capacity of leaf extracts from two Stevia rebaudiana Bertoni varieties adapted to cultivation in Mexico. Nutr Hosp, 31(11):63-70.

Sharma, R.; Yadav, R. and Manivannan, E. (2012): Study of effect of Stevia rebaudiana bertoni on oxidative stress in type-2 diabetic rat models. Biomedicine \& Aging Pathology, 2:126-131.

Van Der Zwaluw, N.L.; Van De Rest, O.; Kessels, R.P.C. and Groot, L.C.P.G.M. (2014): Shortterm effects of glucose and sucrose on cognitive performance and mood in elderly people. J Clin Exp Neuropsychol., 36: (5) 517-527. 
Villareal, L.M.A.; Cruz, R.A.M.; Ples, M.B. and Vitor, R.J.S. (2016): Neurotropic effects of aspartame, stevia and sucralose on memory retention and on the histology of the hippocampus of the ICR mice (Mus musculus). Asian Pac J Trop Biomed, 6(2): 114-118.

White, J.S. (2014): Sucrose, HFCS, and Fructose: History, Manufacture, Composition, Applications, and Production. Nutr Health, p. 13-33.

Yu J.Y. and Frank L.M. (2014): Hippocampal-cortical interaction in decision making. Neurobiol Learn Mem 117C: 34-41.

Zhao, L.; Yang, H.; Xuc, M.; Wang, X.; Wang, C.; Lianc, Y.; Mehmood, A. and Daid, H. (2019): Stevia residue extract ameliorates oxidative stress in D-galactose-induced aging mice via Akt/Nrf2/HO-1 pathway. J FUNCT FOODS, 52:587-595. 


\title{
الملخص باللغة العربية
}

\section{الفرق بين المحليات الطبيعية والاصطناعية: دراسات هنتوباثولوجية على مخ ذكور الجرذان البيضاء (الحصين)}

\author{
عائشة صابر محمد ، نشوي أحمد فوزي الثناوي ، سميرة أحمد عبدالمجيد \\ قسم علم الحيوان - كلية البنات للاداب والعلوم والتربية - جامعة عين شمس
}

تهدف الدراسة المقدمة إلى المقارنة بين الاسبرتام والاستيفيا كمحليات طبيعية وصناعية، قليلة السعرات الحرارية ،

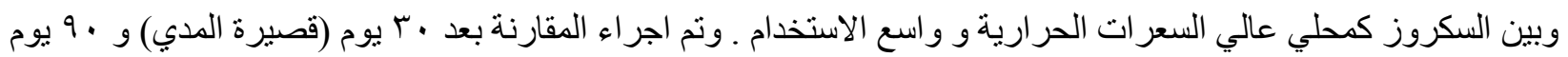

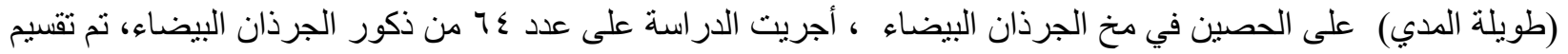

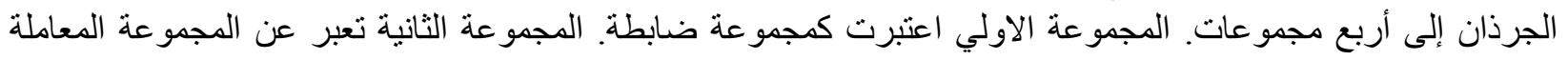

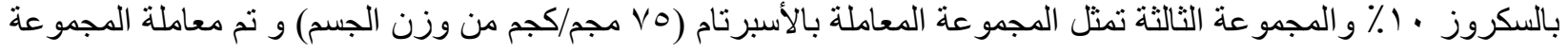

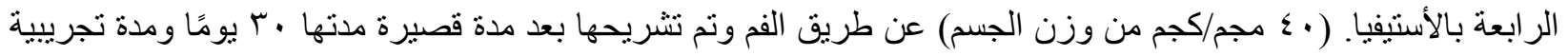

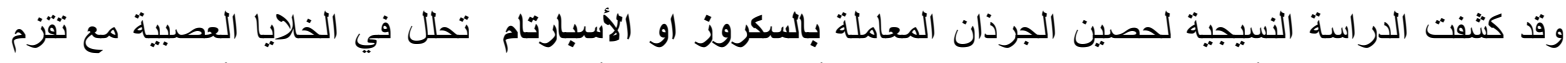

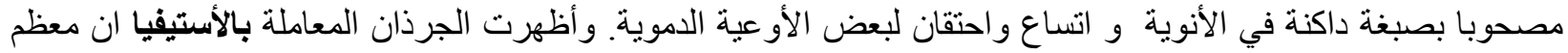

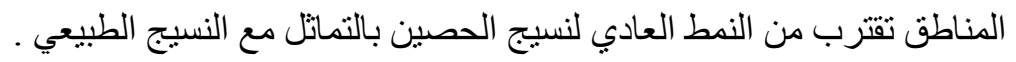

وكذللك اوضحت الدراسة الهستوكيميائية علي انسجة الحصين انخفاضاص كبيرالـ في محتويات البروتين الكلي في

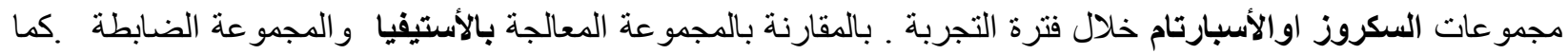

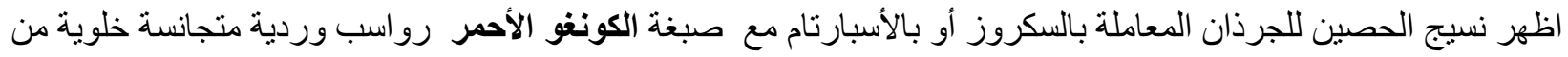
الأميلويد في جميع أنحاء النسيج خلال فترة الدراسة. كما لوحظ ترسبات الأميلويد محدودة او قليلة في مجموعة الألئ الأستيفيا مقارنة بالمجمو عة الضابطة.

لذلك نستخلص ، ان التحلية بالأستيفيا قليلة السعرات الحرارية بديلاً أفضل عن التحلية الاصطناعية بالأسبارنام لأن الاستيفيا لديها

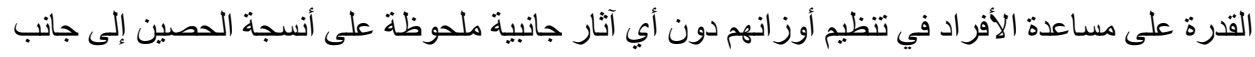

